Research Paper

\title{
Overexpression of Transcobalamin 1 is an Independent Negative Prognosticator in Rectal Cancers Receiving Concurrent Chemoradiotherapy
}

\author{
Yi-Ying Lee ${ }^{1,2}$, Yu-Ching Wei ${ }^{3}$, Yu-Feng Tian 4, 5, Ding-Ping Sun ${ }^{4,6}$, Ming-Jen Sheu 7 , Ching-Chieh Yang ${ }^{8}$ \\ Li-Ching Lin ${ }^{8}$, Chen-Yi Lin 7 , Chung-Hsi Hsing9, Wan-Shan Li10, Chien-Feng Li10, 11, 12, 13, Pei-Ling Hsieh ${ }^{14}$, \\ Ching-Yih $\operatorname{Lin}^{7,15 \bowtie}$ \\ 1. Department of Pathology, Chi Mei Medical Center, Liouying, Tainan, Taiwan; \\ 2. Institute of Biomedical Sciences, National Sun Yat-sen University, Kaohsiung, Taiwan; \\ 3. Department of Pathology, Kaohsiung Municipal Ta-Tung Hospital, Kaohsiung, Taiwan; \\ 4. Division of General Surgery, Department of Surgery, Chi Mei Medical Center, Tainan, Taiwan; \\ 5. Department of Health \& Nutrition, Chia Nan University of Pharmacy and Science, Tainan, Taiwan; \\ 6. Department of Pharmacy, Chia Nan University of Pharmacy and Science, Tainan, Taiwan; \\ 7. Division of Gastroenterology and Hepatology, Department of Internal Medicine, Chi Mei Medical Center, Tainan, Taiwan; \\ 8. Department of Radiation Oncology, Chi Mei Medical Center, Tainan, Taiwan; \\ 9. Department of Anesthesiology, Chi Mei Medical Center, Tainan, Taiwan; \\ 10. Department of Pathology, Kaohsiung Medical University Hospital, Kaohsiung Medical University, Kaohsiung, Taiwan; \\ 11. Department of Pathology, Chi Mei Medical Center, Tainan, Taiwan; \\ 12. National Institute of Cancer Research, National Health Research Institutes, Tainan, Taiwan; \\ 13. Department of Biotechnology, Southern Taiwan University of Science and Technology, Tainan, Taiwan; \\ 14. Department of Medical Image, Chi Mei Medical Center, Tainan, Taiwan; \\ 15. Department of Leisure, Recreation, and Tourism Management, Southern Taiwan.
}

Pei-Ling Hsieh and Ching-Yih Lin contributed equally as co-last authors of this work.

$\triangle$ Corresponding author: Ching-Yih Lin, M.D., Division of Gastroenterology and Hepatology, Department of Internal Medicine, Chi Mei Medical Center, Tainan, Taiwan. E-mail: d840811@mail.chimei.org.tw, TEL: +886-6-2812811 ext. 52000

(c) Ivyspring International Publisher. This is an open access article distributed under the terms of the Creative Commons Attribution (CC BY-NC) license (https://creativecommons.org/licenses/by-nc/4.0/). See http://ivyspring.com/terms for full terms and conditions.

Received: 2016.11.09; Accepted: 2017.03.06; Published: 2017.05.12

\begin{abstract}
Objective: Neoadjuvant concurrent chemoradiotherapy (CCRT) is an increasingly common therapeutic strategy for locally advanced rectal cancer, but stratification of risk and final outcomes remain a major challenge. Transcobalamin 1 (TCN1), a vitamin B12 (cobalamin)-binding protein, regulates cobalamin homeostasis. High expression of TCN1 have been reported in neoplasms such as breast cancer and hepatocellular carcinoma. However, little is known about the relevance of TCN1 to rectal cancer receiving CCRT. This study examined the predictive and prognostic impact of TCNI expression in patients with rectal cancer following neoadjuvant CCRT. Methods: Through data mining from a published transcriptome of rectal cancers (GSE35452), we identified upregulation of TCNI gene as the most significantly predicted poor response to CCRT among ion transport-related genes (GO:0006811). We evaluated TCN1 immunohistochemistry and performed an $\mathrm{H}$-score analysis on endoscopic biopsy specimens from 172 rectal cancer patients receiving neoadjuvant CCRT followed by curative surgery. Expression levels of TCNI were further correlated with clinicopathologic features, therapeutic response, tumor regression grade (TRG) and survivals including metastasis-free survival (MeFS), disease-specific survival (DSS) and recurrent-free survival (LRFS).
\end{abstract}

Results: TCN1 overexpression was significantly related to advanced post-treatment tumor $(T 3, T 4 ; p<0.001)$ and nodal status $(\mathrm{N} 1, \mathrm{~N} 2 ; p<0.001)$, vascular invasion $(p=0.003)$ and inferior tumor regression grade $(p<0.001)$. In survival analyses, TCN1 overexpression was significantly associated with shorter DSS $(p<0.0001)$, MeFS $(p=0.0002)$ and LRFS $(p=0.0001)$. Furthermore, it remained an independent prognosticator of worse DSS $(p=0.002$, hazard ratio=3.344), MeFS $(p=0.021$, hazard ratio $=3.015)$ and LRFS $(p=0.037$, hazard ratio $=3.037)$ in the multivariate comparison.

Conclusion: Overexpression of TCN1 is associated with poor therapeutic response and adverse outcomes in rectal cancer patients receiving CCRT, justifying the potential prognostic value of TCNI in rectal cancer receiving CCRT.

Key words: TCN1, Transcobalamin 1, CCRT, chemoradiotherapy, rectal cancer. 


\section{Introduction}

Colorectal cancer (CRC) ranks as the third most frequent cancer in men and second in women worldwide [1]. Rectal cancers approximately accounts for one-third of CRC and significant effort has been done to achieve better treatment results [2]. Neoadjuvant concurrent chemoradiotherapy (CCRT) followed by surgery remains the preferred therapy for patients with locally advanced rectal cancer LARC, resulting in better sphincter preservation rates and superior survival [3-6]. Nevertheless, up to $15-20 \%$ of these patients receiving neoadjuvant CCRT will eventually develop local recurrence or distant metastases [7, 8]. Therefore, it could be of clinical implication in identifying prognostic biomarkers of LARC in response to CCRT as well as risk stratification for further treatment and development of novel target therapies.

Ion transport across the cell membrane plays an important role in many cellular functions such as cell proliferation, migration and cell death [9-12]. In recent years, it has become more clearly that ion transporters and channels participate in the regulation of cancer development and are critically important for tumor cell survival and metastasis [10-13]. It might have important implications in targeting ion transporters identifying prognostic biomarkers as well as developing suitable therapeutic targets. Therefore, we performed data mining from a published transcriptome of rectal cancers (GSE35452), identifying Transcobalamin I (TCN1) gene as the most significantly upregulated gene among the pathways associated with ion transport-related genes (GO:0006811).

TCN1 [haptocorrin or vitamin B12 (cobalamin) R binder], is one of the three transport proteins that binds vitamin B12 and is present in human serum and various biological fluids [14]. As we know, vitamin B12 plays an important role in maintenance of nervous system function, hematopoiesis, and cell metabolism [14-16]. TCN1 carries vitamin B12 as it passes through the stomach and enzymatically releases it in the duodenum where it is subsequently bound by intrinsic factor (IF) $[15,17,18]$. Interestingly, TCN1 has been reported to be overexpressed in some malignancies such as hepatocellular carcinoma (HCC) and cancers of the breast, lung and stomach [15, 17-24]. Recently, a bioinformatics -based study has suggested that TCN1 as an important oncogene for the classification of normal and CRC tissues [25]. However, little is known about its expression in CRC and the clinical relevance, especially those related to CCRT, has not been systemically established.

In this study, we first identified TCN1 as the most significantly upregulated gene of those involving glutamine metabolism, predicting poor response to neoadjuvant CCRT. Then, we evaluated the clinical correlates of TCN1 expression in a well-characterized study cohort of rectal cancer patients treated with neoadjuvant CCRT.

\section{Materials and methods}

\section{Analysis of published transcriptome dataset}

To identify potential genes involving in response to neoadjuvant CCRT, one public transcriptome of 46 tissue samples from rectal patients receiving neoadjuvant CCRT (GSE35452) was analyzed using Human Genome U133 Plus 2.0 arrays from Affymetrix. The raw CEL files was computerized using statistical software Nexus Expression 3 (BioDiscovery). All probe sets were analyzed without pre-selection. Class comparison and functional profiling were conducted to recognize significant differentially expressed genes, with special attention to pathways involving ion transport-related genes (GO:0006811). We selected those with $p<0.01$ and alteration of $\log 2$-transformed expression at least + /-0.1-fold for further analysis.

\section{Patients and tumor specimens}

We procured formalin-fixed paraffin-embedded (FFPE) tissue specimens from 172 rectal cancer patients with regular follow-up from the archive of Chi Mei Medical Center between 1998 and 2004. This study was approved by the institutional review board (IRB 10302014). All patients were pathologically diagnosed with a rectal adenocarcinoma using a colonendoscopic biopsy, lacking evidence of distant metastasis on imaging examination including chest X-radiography and/or abdominopelvic CT. The criteria for the clinicopathologic evaluation were essentially identical as previously described [26-28]. In general, all patients received had preoperative 5-fluorouracil-baed chemotherapy concomitant to radiotherapy with a total dose of 45 Gy in 25 fractions over a period of five weeks. Adjuvant systemic chemotherapy was boosted if the pre-treatment (Pre-Tx) or post-treatment (Post-Tx) tumor or nodal status was beyond T3 or N1, respectively. All patients were regularly monitored after diagnosis until death or last follow-up.

\section{Histopathologic evaluation}

The pathologic examination of the tumor specimen was evaluated by two pathologists (CF Li and YC Wei) in a blinded manner without prior knowledge of the clinical information. Post-Tx T and $\mathrm{N}$ stages of all patients were classified according to 
the American Joint Committee on Cancer (AJCC) staging manual, 7th edition [29]. Tumor regression grade (TRG) in response to neoadjuvant CCRT is used as the end-point with the histologic assessment described previously [30].

\section{TCN1 immunohistochemistry analysis}

Immunohistochemistry of FFPE tissue sections was performed as previously described [26-28]. Briefly, tissue sections from Pre-Tx rectal tumor biopsies were deparaffinized and rehydrated for TCN1 immunostaining. A blockade of the endogenous peroxidase activity was performed with $3 \% \mathrm{H} 2 \mathrm{O} 2$ for 10 minutes. Slides were washed with Tris buffered saline for $15 \mathrm{~min}$ after blocking and then incubated with a primary anti-TCN1 monoclonal antibody (ab118386, Abcam). The TCN1 staining was interpreted using the H-score, defined by the following equation: $\mathrm{H}$-score $=\Sigma \mathrm{Pi}(\mathrm{i}+1)$ as previously described [31-34]. The staining intensity of the decorated tumor cells was graded from " 0 to $3+$ ", and $\mathrm{Pi}$ is the percentage of the stained tumor cells with various intensities. Tumors with no less than the median of all scored cases were defined as showing high expression of TCN1. Immunohistochemically, TCN1 has been found to be localized to the membrane and cytoplasm of tumor cells $[17,24]$.

\section{Statistical analysis}

All statistical analysis was carried out using SPSS 14 software package. The association of TCN1 expression with clinicopathologic features were conducted using Chi-square test. Rectal cancer-specific survivals including disease-specific survival (DSS), local recurrence-free survival (LRFS), and metastasis-free survival (MeFS) as the endpoints analyzed were calculated as the time interval between the date of surgery and the date of event developed as described in our previous work [35]. Survival curves were plotted by the Kaplan-Meier method and compared using the log-rank tests to evaluate prognostic differences between subgroups. Those parameters demonstrated prognostic significance at univariate level were determined by the Cox multivariate regression analysis. A two tailed $p<0.05$ was considered to be statistically significant for all analyses.

\section{Results}

\section{Upregulation of TCN 1 gene predicts poor response to CCRT}

From the dataset of 46 rectal cancer cases in a public transcriptome GSE35452, we focused on genes related to ion transport (GO:0006811). In non-responders to CCRT, only TCN1 showed significant upregulation (Table-1 and Figure-1). We found that there were ten genes significantly identified in non-responders to CCRT, including TCN1, PLLP, SCNN1A, BEST2, AKAP7, GABRA2, FXYD3, CACNB2, KCNJ2, and TRPM4 (Figure 1 and Table 1). Among these downregulated genes, TCN1 exhibited the top-ranking, upregulated fold change $(\log 2$ ration $=1.5459, p=0.0003)$ (Table 1$)$. It promoted us to further investigate the expression status and clinical relevance of TCN1 in rectal cancers.

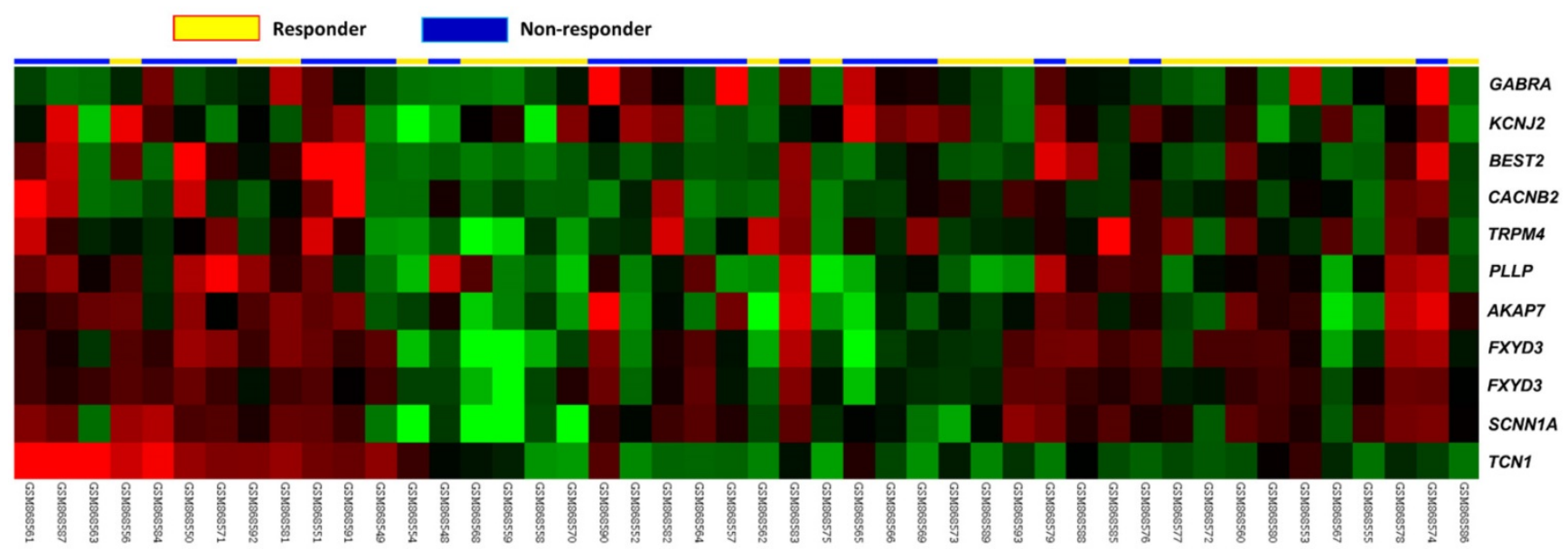

Figure 1. Analysis of gene expression in CCRT responders versus non-responders from a published transcriptomic dataset of rectal cancers. Clustering analysis of genes related to iron transport shows TCN1 is significantly upregulated in patients responsive to CCRT. Tissue specimens from non-responders (blue lines) and responders (yellow lines) are indicated on top of the heatmap, and expression levels of upregulated and downregulated genes are expressed as a spectrum of brightness of red and green, respectively, with those unaltered in mRNA 
Table 1. Summary of differentially expressed genes associated with ion transport (GO:0006811) in relation to response to CCRT in rectal carcinoma

\begin{tabular}{|c|c|c|c|c|c|c|}
\hline Probe & $\begin{array}{l}\text { Comparison } \\
\log \text { ratio }\end{array}$ & $\begin{array}{l}\text { Comparison } \\
\text { p-value }\end{array}$ & $\begin{array}{l}\text { Gene } \\
\text { Symbol }\end{array}$ & Gene Name & Biological Process & Molecular Function \\
\hline $\begin{array}{l}205513 \\
\text { at }\end{array}$ & 1.5459 & 0.0003 & TCN1 & $\begin{array}{l}\text { transcobalamin I (vitamin } \\
\text { B12 binding protein; } \mathrm{R} \\
\text { binder family) }\end{array}$ & $\begin{array}{l}\text { cobalamin transport, cobalt ion } \\
\text { transport, ion transport, } \\
\text { transport }\end{array}$ & $\begin{array}{l}\text { cobalamin binding, cobalt ion binding, cobalt ion } \\
\text { transmembrane transporter activity }\end{array}$ \\
\hline $\begin{array}{l}204519 \\
\text { _s_at }\end{array}$ & 1.1474 & $<0.0001$ & PLLP & $\begin{array}{l}\text { plasma membrane } \\
\text { proteolipid (plasmolipin) }\end{array}$ & ion transport, transport & ion channel activity \\
\hline $\begin{array}{l}203453 \\
\text { at }\end{array}$ & 1.1402 & 0.0001 & $\begin{array}{l}\text { SCNN1 } \\
\text { A }\end{array}$ & $\begin{array}{l}\text { sodium channel; } \\
\text { nonvoltage-gated } 1 \text { alpha }\end{array}$ & $\begin{array}{l}\text { excretion, ion transport, } \\
\text { response to stimulus, sodium } \\
\text { ion transport, transport }\end{array}$ & $\begin{array}{l}\text { amiloride-sensitive sodium channel activity, ion } \\
\text { channel activity, protein binding, sodium channel } \\
\text { activity, sodium ion binding }\end{array}$ \\
\hline $\begin{array}{l}207432 \\
\text { at }\end{array}$ & 0.8953 & 0.0004 & BEST2 & bestrophin 2 & ion transport, transport & $\begin{array}{l}\text { calcium ion binding, chloride channel activity, } \\
\text { chloride ion binding, ion channel activity }\end{array}$ \\
\hline $\begin{array}{l}205771 \\
\text { _s_at }\end{array}$ & 0.8460 & 0.0013 & $A K A P 7$ & $\begin{array}{l}\text { A kinase (PRKA) anchor } \\
\text { protein } 7\end{array}$ & $\begin{array}{l}\text { intracellular signaling cascade, } \\
\text { ion transport, protein } \\
\text { localization }\end{array}$ & kinase activity, protein kinase A binding \\
\hline $\begin{array}{l}207014 \\
\text { at }\end{array}$ & 0.8246 & 0.0001 & $\begin{array}{l}\text { GABRA } \\
2\end{array}$ & $\begin{array}{l}\text { gamma-aminobutyric } \\
\text { acid (GABA) A receptor; } \\
\text { alpha } 2\end{array}$ & $\begin{array}{l}\text { chloride transport, } \\
\text { gamma-aminobutyric acid } \\
\text { signaling pathway, ion } \\
\text { transport, regulation of } \\
\text { neurotransmitter levels, } \\
\text { transport }\end{array}$ & $\begin{array}{l}\text { GABA-A receptor activity, benzodiazepine } \\
\text { receptor activity, chloride channel activity, } \\
\text { chloride ion binding, extracellular ligand-gated } \\
\text { ion channel activity, ion channel activity, } \\
\text { neurotransmitter receptor activity }\end{array}$ \\
\hline $\begin{array}{l}202488 \\
\text { _S_at }\end{array}$ & 0.8124 & 0.0005 & FXYD3 & $\begin{array}{l}\text { FXYD domain containing } \\
\text { ion transport regulator } 3\end{array}$ & $\begin{array}{l}\text { chloride transport, ion transport, } \\
\text { transport }\end{array}$ & $\begin{array}{l}\text { chloride channel activity, chloride ion binding, ion } \\
\text { channel activity }\end{array}$ \\
\hline $\begin{array}{l}202489 \\
\text { _S_at }\end{array}$ & 0.5951 & 0.0018 & FXYD3 & $\begin{array}{l}\text { FXYD domain containing } \\
\text { ion transport regulator } 3\end{array}$ & $\begin{array}{l}\text { chloride transport, ion transport, } \\
\text { transport }\end{array}$ & $\begin{array}{l}\text { chloride channel activity, chloride ion binding, ion } \\
\text { channel activity }\end{array}$ \\
\hline $\begin{array}{l}213714 \\
\text { at }\end{array}$ & 0.5807 & 0.0001 & $\begin{array}{l}C A C N B \\
2\end{array}$ & $\begin{array}{l}\text { calcium channel; } \\
\text { voltage-dependent; beta } 2 \\
\text { subunit }\end{array}$ & $\begin{array}{l}\text { calcium ion transport, ion } \\
\text { transport, neuromuscular } \\
\text { junction development, transport }\end{array}$ & $\begin{array}{l}\text { calcium channel activity, calcium ion binding, ion } \\
\text { channel activity, voltage-gated calcium channel } \\
\text { activity, voltage-gated ion channel activity }\end{array}$ \\
\hline $\begin{array}{l}206765 \\
\text { at }\end{array}$ & 0.5684 & 0.0093 & KCNJ2 & $\begin{array}{l}\text { potassium } \\
\text { inwardly-rectifying } \\
\text { channel; subfamily J; } \\
\text { member } 2\end{array}$ & $\begin{array}{l}\text { ion transport, potassium ion } \\
\text { transport, transport }\end{array}$ & $\begin{array}{l}\text { inward rectifier potassium channel activity, ion } \\
\text { channel activity, potassium ion binding, protein } \\
\text { binding, voltage-gated ion channel activity }\end{array}$ \\
\hline $\begin{array}{l}219360 \\
\text { s_at }\end{array}$ & 0.5391 & 0.0057 & TRPM4 & $\begin{array}{l}\text { transient receptor } \\
\text { potential cation channel; } \\
\text { subfamily M; member } 4\end{array}$ & $\begin{array}{l}\text { immune response, ion transport, } \\
\text { transport }\end{array}$ & $\begin{array}{l}\text { ATP binding, calcium ion binding, calmodulin } \\
\text { binding, ion channel activity, nucleotide binding, } \\
\text { receptor activity }\end{array}$ \\
\hline
\end{tabular}

\section{Immunohistochemical expression of TCN1 and its association with clinicopathologic features}

To evaluate the relationship between TCN1 expression levels and clinicopathologic characteristics of rectal cancers treated with neoadjuvant CCRT, immunohistochemistry was performed to examine the expression of TCN1 in 172 rectal cancer specimens. Cytoplasmic expression of TCN1 was successfully scored in all examined cases with a wide range of H-scores, varying from 100 to 290 (Figure-2). As summarized in Table-2, TCN1 upregulation was correlated with an advanced Post-Tx tumor and nodal status (Both $p<0.001$ ) as well as the presence of vascular invasion $(p=0.003)$. Moreover, TCN1 overexpression was found to be significantly associated with lesser degree of tumor regression $(p<0.001)$. In the group of high TCN1 expression, there were $27(15.7 \%)$ patients with tumor regression grade $0-1,58(33.7 \%)$ patients with grade $2-3$, and $1(0.6 \%)$ patients with grade 4 . In the group of low TCN1 expression, by contrast, there were $10(5.8 \%)$ patients with tumor regression grade $0-1,60(34.9 \%)$ patients with grade 2-3, and $16(9.3 \%)$ patients with grade 4 .
Table 2. Associations and comparisons between TCNI expression and clinicopathological factors in 172 rectal cancer patients receiving neoadjuvant CCRT.

\begin{tabular}{|c|c|c|c|c|c|}
\hline \multirow[t]{2}{*}{ Parameter } & & \multirow[t]{2}{*}{ No. } & \multicolumn{2}{|c|}{ TCN1 Expression } & \multirow[t]{2}{*}{$p$-value } \\
\hline & & & Low Exp. & High Exp. & \\
\hline \multirow[t]{2}{*}{ Gender } & Male & 108 & 54 & 54 & 1.000 \\
\hline & Female & 64 & 32 & 32 & \\
\hline \multirow[t]{2}{*}{ Age } & $<70$ & 106 & 48 & 58 & 0.117 \\
\hline & $\geqq 70$ & 66 & 38 & 28 & \\
\hline \multirow{2}{*}{$\begin{array}{l}\text { Pre-Tx tumor status } \\
(\text { Pre-T) }\end{array}$} & T1-T2 & 81 & 41 & 40 & 0.879 \\
\hline & T3-T4 & 91 & 45 & 46 & \\
\hline \multirow{2}{*}{$\begin{array}{l}\text { Pre-Tx nodal status } \\
\text { (Pre-N) }\end{array}$} & No & 125 & 68 & 57 & 0.060 \\
\hline & N1-N2 & 47 & 18 & 29 & \\
\hline \multirow{2}{*}{$\begin{array}{l}\text { Post-Tx tumor status } \\
(\text { Post-T) }\end{array}$} & $\mathrm{T} 1-\mathrm{T} 2$ & 86 & 57 & 29 & $<0.001^{*}$ \\
\hline & $\mathrm{T} 3-\mathrm{T} 4$ & 86 & 29 & 57 & \\
\hline \multirow{2}{*}{$\begin{array}{l}\text { Post-Tx nodal status } \\
(\text { Post-N) }\end{array}$} & No & 123 & 74 & 49 & $<0.001^{*}$ \\
\hline & N1-N2 & 49 & 12 & 37 & \\
\hline \multirow[t]{2}{*}{ Vascular invasion } & Absent & 157 & 84 & 73 & $0.003^{*}$ \\
\hline & Present & 15 & 2 & 13 & \\
\hline \multirow{2}{*}{ Perineural invasion } & Absent & 167 & 85 & 82 & 0.173 \\
\hline & Present & 5 & 1 & 4 & \\
\hline \multirow[t]{3}{*}{ Tumor regression grade } & $\begin{array}{l}\text { Grade } \\
0-1\end{array}$ & 37 & 10 & 27 & $<0.001^{*}$ \\
\hline & $\begin{array}{l}\text { Grade } \\
2 \sim 3\end{array}$ & 118 & 60 & 58 & \\
\hline & Grade 4 & 17 & 16 & 1 & \\
\hline
\end{tabular}




\section{Prognostic impact of TCN1 expression in rectal cancer}

In addition, we analyzed the prognostic significance of TCN1 expression in patients with rectal cancer. The mean follow-up time of these patients was 48.2 months (range, 6.2 to 131.2). At the univariate level, clinicopathologic parameters including the Pre-Tx tumor and positive lymph node metastasis, Post-Tx tumor and nodal statuses, presence of vascular invasion, and TRG were predictive of at least one of the three endpoints of this study (Table-3). Notably, patients with high expression of TCN1 were characterized by a more aggressive clinical course, with significantly poorer DSS ( $p<0.0001$; Figure-3), LRFS ( $p=0.0001$; Figure- 3 ) and MeFS $(p=0.0002 ;$ Figure-3). At multivariate comparisons, TRG and TCN1 expression remained to be shown as independent prognostic factors. High expression of TCN1 was independent predictive for DFS $(p=0.002$, hazard ratio $=3.344)$, LRFS $(p=0.037$, hazard ratio $=3.037)$ and MeFS $(p=0.021$, hazard ratio $=3.015)($ Table-4).
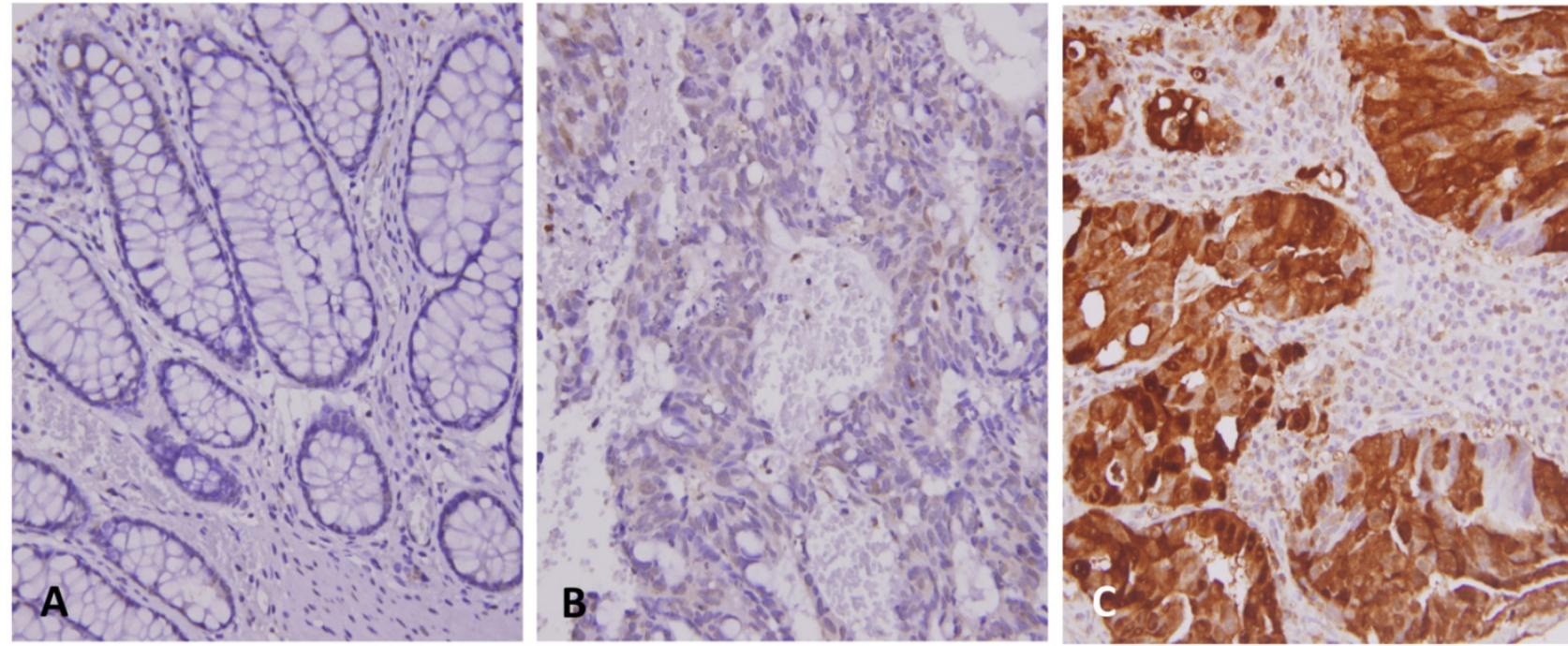

Figure 2. Representative immunostainings of TCN1 expression. The non-neoplastic colonic mucosa (A) reveals no expression of TCNI as compared with rectal cancers with low expression (B) and high expression (C) of TCNI in pre-treatment specimens.
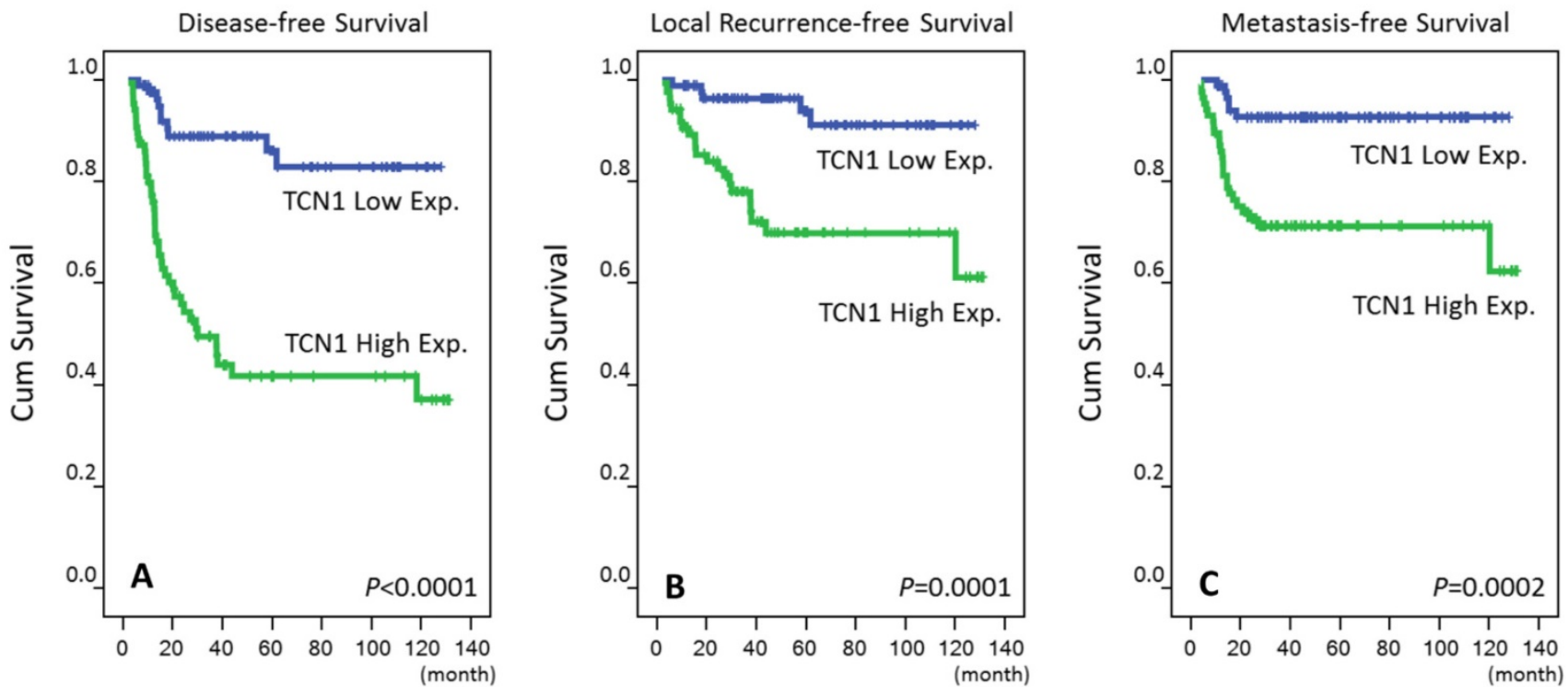

Figure 3. Kaplan-Meier survival curves plotted to predict survival. Using the log-rank test, high expression of TCNI predicts inferior disease-specific survival (A) as well as local recurrence-free survival (B). It also significantly predicts metastasis-free survival (C). 
Table 3. Univariate log-rank analysis for important clinicopathological variables and TCN1 expression

\begin{tabular}{|c|c|c|c|c|c|c|c|c|}
\hline \multirow[t]{2}{*}{ Parameter } & & \multirow[t]{2}{*}{ No. of case } & \multicolumn{2}{|l|}{ DFS } & \multicolumn{2}{|l|}{ LRFS } & \multicolumn{2}{|l|}{ MeFS } \\
\hline & & & No. of event & $p$-value & No. of event & $p$-value & No. of event & $p$-value \\
\hline \multirow[t]{2}{*}{ Gender } & Male & 108 & 34 & 0.6344 & 20 & 0.2250 & 17 & 0.3520 \\
\hline & Female & 64 & 20 & & 7 & & 14 & \\
\hline \multirow[t]{2}{*}{ Age } & $<70$ & 106 & 35 & 0.6999 & 18 & 0.6615 & 20 & 0.7427 \\
\hline & $\geqq 70$ & 66 & 19 & & 9 & & 11 & \\
\hline \multirow[t]{2}{*}{ Pre-Tx tumor status (Pre-T) } & $\mathrm{T} 1-\mathrm{T} 2$ & 81 & 20 & $0.0486^{*}$ & 10 & 0.2261 & 11 & 0.1745 \\
\hline & $\mathrm{T} 3-\mathrm{T} 4$ & 91 & 34 & & 17 & & 20 & \\
\hline \multirow[t]{2}{*}{ Pre-Tx nodal status (Pre-N) } & N0 & 125 & 33 & $0.0010^{*}$ & 15 & $0.0070^{*}$ & 19 & 0.0973 \\
\hline & N1-N2 & 47 & 21 & & 12 & & 12 & \\
\hline \multirow[t]{2}{*}{ Post-Tx tumor status (Post-T) } & T1-T2 & 86 & 15 & $0.0002^{*}$ & 7 & $0.0040^{*}$ & 8 & $0.0033^{*}$ \\
\hline & $\mathrm{T} 3-\mathrm{T} 4$ & 86 & 39 & & 20 & & 23 & \\
\hline \multirow[t]{2}{*}{ Post-Tx nodal status (Post-N) } & No & 123 & 35 & 0.2338 & 16 & 0.1320 & 20 & 0.4634 \\
\hline & N1-N2 & 49 & 19 & & 11 & & 11 & \\
\hline \multirow[t]{2}{*}{ Vascular invasion } & Absent & 157 & 45 & $0.0029^{*}$ & 21 & $0.0028^{*}$ & 27 & 0.4470 \\
\hline & Present & 15 & 9 & & 6 & & 4 & \\
\hline \multirow[t]{2}{*}{ Perineural invasion } & Absent & 167 & 51 & 0.0647 & 25 & 0.0940 & 30 & 0.9083 \\
\hline & Present & 5 & 3 & & 2 & & 1 & \\
\hline \multirow[t]{3}{*}{ Tumor regression grade } & Grade $0-1$ & 37 & 23 & $<0.0001^{*}$ & 10 & $0.0090^{*}$ & 14 & $0.0006^{*}$ \\
\hline & Grade 2 3 & 118 & 30 & & 17 & & 16 & \\
\hline & Grade 4 & 17 & 1 & & 0 & & 1 & \\
\hline \multirow[t]{2}{*}{ TCN1 expression } & Low Exp. & 86 & 10 & $<0.0001^{*}$ & 5 & $0.0001^{*}$ & 6 & $0.0002^{*}$ \\
\hline & High Exp. & 86 & 44 & & 22 & & 25 & \\
\hline
\end{tabular}

DFS, disease-free survival; LRFS, local (pelvic) recurrence-free survival; MeFS, metastasis-free survival; ${ }^{*}$, statistically significant

Table 4. Multivariate analysis

\begin{tabular}{|c|c|c|c|c|c|c|c|c|c|}
\hline \multirow[t]{2}{*}{ Parameter } & \multicolumn{3}{|l|}{ DFS } & \multicolumn{3}{|l|}{ LRFS } & \multicolumn{3}{|c|}{ MeFS } \\
\hline & H.R. & $95 \% \mathrm{CI}$ & $p$-Value & H.R. & $95 \% \mathrm{CI}$ & $p$-Value & H.R. & $95 \% \mathrm{CI}$ & $p$-Value \\
\hline Tumor regression grade & 2.381 & $1.360-4.167$ & $0.002^{*}$ & 1.992 & $0.906-4.386$ & 0.087 & 2.096 & $1.008-4.237$ & $0.048^{*}$ \\
\hline TCN1 expression & 3.344 & $1.572-7.116$ & $0.002^{*}$ & 3.037 & $1.062-8.685$ & $0.037^{*}$ & 3.015 & $1.177-7.721$ & $0.021^{*}$ \\
\hline Vascular invasion & 1.783 & $0.806-3.943$ & 0.153 & 1.958 & $0.715-5.364$ & 0.191 & - & - & - \\
\hline Post-Tx tumor status (Post-T) & 1.382 & $0.730-2.616$ & 0.320 & 1.701 & $0.686-4.216$ & 0.251 & 1.766 & $0.752-4.149$ & 0.192 \\
\hline Pre-Tx nodal status (Pre-N) & 1.467 & $0.759-2.838$ & 0.254 & 2.007 & $0.864-4.661$ & 0.105 & - & - & - \\
\hline Pre-Tx tumor status (Pre-T) & 1.476 & $0.770-2.827$ & 0.241 & - & - & - & - & - & - \\
\hline
\end{tabular}

DFS, disease-free survival; LRFS, local (pelvic) recurrence-free survival; MeFS, metastasis-free survival; *, statistically significant

\section{Discussion}

During the last decades, there has a great improvement in the care of patients with LARC and neoadjuvant CCRT followed by surgery is the current standard treatment strategy [3-6]. Unfortunately, current treatment for LARC patients with neoadjuvant CCRT demonstrates disappointing results $[7,8]$. Therefore, it is essential to develop effective predictive biomarkers, not only for prognostication, but also to individualize treatment for patients with rectal cancers. In the present study, we have shown that overexpression of TCN1 was correlated with aggressive biological behaviors and poor clinical outcomes in rectal cancers. In accordance with the pathologic variable analysis, there was a strong correlation with poor survivals including DFS, LRFS and MeFS. Moreover, overexpression of TCN1 was predictive of low tumor regression after neoadjuvant CCRT, suggesting that TCN1 could be a potential therapeutic target of rectal cancers and/or could be a biomarker for monitoring the efficiency of therapy.
TCN1 is a $60-70 \mathrm{kDa}$ molecular weight protein, derived from the granulocyte line [36, 37]. TCN1 participates in vitamin B12 homeostasis together with another two vitamin B12 binding proteins (intrinsic factor and TCN2) [38]. Elevated serum levels of vitamin B12 and TCN1 have been reported in patients with cancers [18, 21, 39]. Furthermore, it has been well elucidated the associations between high serum levels of vitamin B12 and malignant hematological diseases such as chronic myeloid leukemia and acute leukemia and the pathogenesis involves release of TCN1 by proliferating granulocytes [36, 37, 40]. In addition, upregulation of TCN1 both in plasm and tumor tissue have been reported in a number of solid neoplasms including HCC, salivary gland tumors, cancers of the breast, kidney, lung and stomach, and endocervical adenocarcinoma $[15,17-24,41]$. Previous studies have suggested that increased serum level and expression of TCN1 in patients with HCC or secondary liver metastasis might be due to a diminished clearance of TCN1 in the liver [38, 42]. On the other hand, overexpression of TCN1 in other solid malignancies has been inferred mainly to be an excess synthesis of 
its production by tumor cells themselves or to an increase of hypergranulocytosis [17, 36, 38]. Moreover, TCN1 rather than vitamin B12 was found to be better correlated with progression in patients with gastric cancer [20]. Chu et al recently identified TCN1 as a significantly expressed gene that is associated with advanced CRC by microarray meta-analysis [25]. Our results of the present study provide additional evidence that expression status of TCN1 was more produced in tumor cells in parallel to previous research works, suggesting $\mathrm{TCN} 1$ as a marker of disease progression in CRC.

Vitamin B12, an ubiquitous coenzyme mainly involving the synthesis of DNA, plays an important role in cell division and cellular metabolism [36, 43]. Elevated serum vitamin B12 levels have been found to be associated with increased cancer risk and mortality risk in both cancer and non-cancer patients [40, 44, 45]. Some studies have also suggested the degree of elevated plasm vitamin B12 level as a poor prognosticator in certain tumors, particularly of the liver [46, 47]. The mechanisms implicated in the genesis of elevated serum vitamin B12, as addressed above, might be due to a decrease in hepatic clearance or an increase in TCN1 production [36, 40]. Monitoring of serum vitamin B12 and TCN1 may be of specific clinical value in both the initial and subsequent evaluation of response to treatment in patients associated with increased vitamin B12-binding protein synthesis [21]. In addition, rapidly dividing cells such as cancer cells need certain vitamins including vitamin B12, folic acid, biotin and riboflavin for tumor growth and survival [48, 49]. It has been reported that receptors involved in vitamin B12-binding and uptake, including TCN1 and TCN2, are overexpressed in various malignancies [15, 17-24, 41, 49]. Previous studies showed that TCN2 involving one-carbon metabolism pathway was associated with increased risk of colorectal adenoma but the relationship between TCN2 and CRC was inclusive [50-52]. In the present study, we demonstrated that TCN1 was expressed in rectal cancers and its overexpression was associated with advanced disease status. Waibel et al [17] suggested the use of a new synthetic cobalamin analog specifically to bind to TCN1 instead of TCN2 to deliver vitamin-conjugated compounds to tumor sites. In their study, high expression of TCN1 immunohistochemistry was found in various kinds of tumors including colorectal cancers, findings in parallel to the present study results [17]. Thus, we hypothesized that tumors might express vitamin B12 -binding proteins such as TCN1 to satisfy the high demand of cobalamin. Accordingly, vitamin B12 could be as a potential targeting agent in both CRC diagnosis and anticancer therapy through
TCN1-mediated binding $[17,48,49]$.

Several issues must be considered in the present study. First, we did not investigate endogenous TCN1 mRNA and protein levels in CRC through Western blot or reverse transcription polymerase chain reaction that could further support the observed overexpression of $\mathrm{TCN} 1$ as a poor prognostic factor. Second, we did not evaluate the pre-and post-treatment serum levels of cobalamin and TCN1 in our patient cohort, partially owing to an incomplete per-operative study. Although a high level of TCN1 in plasma is not specific to CRC cancer, its decrease after therapeutic intervention may be useful in monitoring the clinical course of the disease. A large-scale study may be required to clarify the association between the serum levels of cobalamin and TCN1 and expression of TCN1 in CRC.

In summary, this study was the first to demonstrate that overexpression of TCN1 was closely associated with low tumor regression and an aggressive biological behavior of patients with rectal cancers receiving neoadjuvant CCRT. The strong inverse correlation with survivals in rectal cancer suggested that overexpression of TCN1 was an independent negative prognosticator. In addition, a better understanding of the role of TCN1 expression in rectal cancer and its relationship with CCRT effect may have potential as a prognostic and therapeutic target.

\section{Acknowledgements}

This study was supported by grants from Kaohsiung Medical University "Aim for the Top Universities" (KMU-TP104E31, KMU-TP104G00, KMU-TP104G01, KMU-TP104G04), the health and welfare surcharge of tobacco products, Ministry of Health and Welfare (MOHW105-TDU-B-212-134007), Ministry of Science and Technology (MOST103-2314-B-037-059-MY3), and Kaohsiung Medical University Hospital (KMUH-OR41, KMUH101-1R46). This work was also supported by grants from Chi Mei Medical Center, Liouying, Taiwan to YY Lee (CLFHR10534). The authors appreciate the BioBank of Chi Mei Medical Center to provide tumor samples.

\section{Competing Interests}

The authors have declared that no competing interest exists.

\section{References}

1. Torre LA, Bray F, Siegel RL, et al. Global cancer statistics, 2012. CA Cancer J Clin. 2015;65:87-108.

2. Resende HM, Jacob LFP, Quinellato LV, et al. Combination chemotherapy versus single-agent chemotherapy during preoperative chemoradiation for resectable rectal cancer. Cochrane Database Syst Rev 2015, (10): CD008531. DOI: 10.1002/14651858.CD008531.pub2. 
3. Valentini V, Coco C, Picciocchi A, et al. Does downstaging predict improved outcome after preoperative chemoradiation for extraperitoneal locally advanced rectal cancer? A long-term analysis of 165 patients. Int J Radiat Oncol Biol Phys. 2002;53:664-674.

4. Crane $\mathrm{CH}$, Skibber JM, Feig BW, et al. Response to preoperative chemoradiation increases the use of sphincter-preserving surgery in patients with locally advanced low rectal carcinoma. Cancer. 2003;97:517-524.

5. Rödel C, Martus P, Papadoupolos T, et al. Prognostic significance of tumor regression after preoperative chemoradiotherapy for rectal cancer. J Clin Oncol. 2005;23:8688-8696.

6. An $\mathrm{X}$, Lin $\mathrm{X}$, Wang $\mathrm{FH}$, et al. Short term results of neoadjuvant chemoradiotherapy with fluoropyrimidine alone or in combination with oxaliplatin in locally advanced rectal cancer: a meta analysis. Eur J Cancer. 2013;49:843-851.

7. van den Brink $M$, Stiggelbout $A M$, van den Hout WB, et al. Clinical nature and prognosis of locally recurrent rectal cancer after total mesorectal excision with or without preoperative radiotherapy. J of Clin Oncol. 2004;22:3958-3964.

8. Guillem JG, Chessin DB, Cohen AM, et al. Long-term oncologic outcome following preoperative combined modality therapy and total mesorectal excision of locally advanced rectal cancer. Ann Surg. 2005;241:829-836.

9. Lang F, Stournaras C. Ion channels in cancer: Future perspectives and clinical potential. Philos Trans R Soc Lond B Biol Sci. 2014;369:20130108.

10. Oosterwijk E, Gillies RJ. Targeting ion transport in cancer. Philos Trans R Soc Lond B Biol Sci. 2014:369:20130107.

11. Villalobos C, Sobradillo D, Hernandez-Morales M, Nunez L. Remodeling of calcium entry pathways in cancer. Adv Exp Med Biol. 2016;898:449-466.

12. Djamgoz MB, Onkal R. Persistent current blockers of voltage-gated sodium channels: A clinical opportunity for controlling metastatic disease. Recent Pat Anticancer Drug Discov. 2013;8:66-84.

13. Roderick HL, Cook SJ. Ca2+ signalling checkpoints in cancer: Remodelling ca2+ for cancer cell proliferation and survival. Nat Rev Cancer. 2008:8:361-375.

14. Burger RL, Mehlman CS, Allen RH: Human plasma r-type vitamin B12-binding proteins. I. Isolation and characterization of transcobalamin i. Transcobalamin iii. And the normal granulocyte vitamin B12-binding protein. J Biol Chem. 1975;250:7700-7706.

15. Chong LY, Cheok PY, Tan WJ, et al. Keratin 15, transcobalamin i and homeobox gene Hox-B13 expression in breast phyllodes tumors: Novel markers in biological classification. Breast Cancer Res Treat. 2012;132:143-151.

16. Morkbak AL, Poulsen SS, Nexo E. Haptocorrin in humans. Clin Chem Lab Med. 2007;45:1751-1759.

17. Waibel $\mathrm{R}$, Treichler $\mathrm{H}$, Schaefer NG, et al. New derivatives of vitamin b12 show preferential targeting of tumors. Cancer Res. 2008;68:2904-2911.

18. Carmel R. Extreme elevation of serum transcobalamin $i$ in patients with metastatic cancer. N Engl J Med. 1975;292:282-284.

19. Gimsing P, Hippe E. Increased concentration of transcobalamin i in a patient with metastatic carcinoma of the breast. Scand J Haematol. 1978;21:243-249.

20. Wakatsuki $\mathrm{Y}$, Inada $\mathrm{M}, \mathrm{Kudo} \mathrm{H}$, et al. Immunological characterization and clinical implication of cobalamin binding protein in human gastric cancer. Cancer Res. 1989;49:3122-3128.

21. Sheppard K, Bradbury DA, Davies JM, Ryrie DR: Cobalamin and folate binding proteins in human tumour tissue. J Clin Pathol 1984;37:1336-1338.

22. Ogawa K, Shima N, Ohshio G, et al. Distribution of vitamin B12 R-binder in lung tumors. Implications for cell differentiation. Pathol Res Pract. 1989;184:234-241.

23. Ogawa K, Ogawa O, Koshiba M, et al. Immunohistochemical localization of vitamin B12 R-binder in salivary gland tumors. Implications for cell differentiation. Pathol Res Pract. 1990;186:751-758.

24. Kim YC, Ogawa K, Wakatsuki Y, et al. Immunohistochemical localization of vitamin B12 R-binder in uterine cervical and endometrial adenocarcinomas. Acta Hist Cyto. 1993;26:507-14.

25. Chu CM, Yao CT, Chang YT, et al. Gene expression profiling of colorectal tumors and normal mucosa by microarrays meta-analysis using prediction analysis of microarray, artificial neural network, classification, and regression trees. Dis Markers. 2014;2014:634123.

26. Sheu MJ, Li CF, Lin CY, et al. Overexpression of anxa1 confers independent negative prognostic impact in rectal cancers receiving concurrent chemoradiotherapy. Tumour Biol. 2014;35:7755-7763.

27. Lee $\mathrm{YY}, \mathrm{Li} \mathrm{CF}$, Lin CY et al. Overexpression of cps 1 is an independent negative prognosticator in rectal cancers receiving concurrent chemoradiotherapy. Tumour Biol. 2014;35:11097-11105.

28. $\mathrm{Li} \mathrm{CF}, \mathrm{He} \mathrm{HL}$, Wang JY, et al. Fibroblast growth factor receptor 2 overexpression is predictive of poor prognosis in rectal cancer patients receiving neoadjuvant chemoradiotherapy. J Clin Pathol 2014;67:1056-1061.

29. Edge SB, Compton CC. The American Joint Committee on Cancer: the 7th edition of the AJCC cancer staging manual and the future of TNM. Ann Surg Oncol. 2010;17:1471-1474.

30. Hsiao CW, Huang WY, Ke TW, et al. Association between irritable bowel syndrome and colorectal cancer: A nationwide populationbased study. Eur J Intern Med. 2014;25:82-86.

31. Chang IW, Wang YH, Wu WJ, et al. Necdin Overexpression Predicts Poor Prognosis in Patients with Urothelial Carcinomas of the Upper Urinary Tract and Urinary Bladder. J Cancer. 2016;7(3):304-13.

32. Ma LJ, Wu WJ, Wang YH, et al. SPOCK1 Overexpression Confers a Poor Prognosis in Urothelial Carcinoma. J Cancer. 2016;7(4):467-76.
33. Liao KM, Chao TB, Tian YF, et al. Overexpression of the PSAT1 Gene in Nasopharyngeal Carcinoma Is an Indicator of Poor Prognosis. J Cancer. 2016;7(9):1088-94.

34. Wu YT, Yen SL, Li CF, et al. Overexpression of Transient Receptor Protein Cation Channel Subfamily A Member 1, Confers an Independent Prognostic Indicator in Nasopharyngeal Carcinoma. J Cancer. 2016;7(10):1181-8.

35. Lin CY, Lee YE,Tian YF, et al. High Expression of EphA4 Predicted Lesser Degree of Tumor Regression After Neoadjuvant Chemoradiotherapy in Rectal Cancer. J Cancer 2017; in press.

36. Andres E, Serraj $\mathrm{K}$, Zhu J, et al. The pathophysiology of elevated vitamin B12 in clinical practice. OJM. 2013;106:505-515.

37. Gimsing P, Overballe-Petersen C, Hippe E. Cobalamin and cobalamin-binding proteins in plasma related to the clinical condition in chronic myelogenous leukemia. Leukemia. 1995;9:1604-1609.

38. Ermens AA, Vlasveld LT, Lindemans J. Significance of elevated cobalamin (vitamin B12) levels in blood. Clin Biochem. 2003;36:585-590.

39. Carmel R, Eisenberg L. Serum vitamin B12 and transcobalamin abnormalities in patients with cancer. Cancer, 1977;40:1348-1353.

40. Arendt JF, Nexo E. Unexpected high plasma cobalamin : proposal for a diagnostic strategy. Clin Chem Lab Med. 2013;51:489-496.

41. Ogawa K, Kudo H, Kim YC, et al. Immunohistochemical distribution of vitamin B12 R-binder in renal cell carcinoma. Virchows Arch A Pathol Anat Histopathol. 1987;412:23-26.

42. Lildballe DL, Nguyen KQ, Poulsen SS, et al. Haptocorrin as marker of disease progression in fibrolamellar hepatocellular carcinoma. Eur J Surg Oncol. 2011;37:72-79.

43. Solomon LR. Disorders of cobalamin (vitamin B12) metabolism: Emerging concepts in pathophysiology, diagnosis and treatment. Blood Rev. 2007;21:113-130.

44. Arendt JF, Pedersen L, Nexo E, et al. Elevated plasma vitamin B12 levels as a marker for cancer: A population-based cohort study. J Natl Cancer Inst. 2013:105:1799-1805.

45. Arendt JF, Farkas DK, Pedersen L, et al. Elevated plasma vitamin B12 levels and cancer prognosis: A population-based cohort study. Cancer Epidemiol. 2016:40:158-165.

46. Kane SP, Murray-Lyon IM, Paradinas FJ, et al. Vitamin b12 binding protein as a tumour marker for hepatocellular carcinoma. Gut. 1978;19:1105-1109.

47. Wheeler K, Pritchard J, Luck W, Rossiter M. Transcobalamin i as a "marker" for fibrolamellar hepatoma. Med Pediatr Oncol. 1986;14:227-229.

48. Gupta Y, Kohli DV, Jain SK. Vitamin b12-mediated transport: A potential tool for tumor targeting of antineoplastic drugs and imaging agents. Crit Rev Ther Drug Carrier Syst. 2008;25:347-379.

49. Russell-Jones G, McTavish K, McEwan J, Rice J, Nowotnik D. Vitamin-mediated targeting as a potential mechanism to increase drug uptake by tumours. J Inorg Bioche. 2004;98:1625-1633.

50. Hazra A, Fuchs CS, Kawasaki T, Kirkner GJ, Hunter DJ, Ogino S. Germline polymorphisms in the one-carbon metabolism pathway and DNA methylation in colorectal cancer. Cancer Causes Control. 2010;21:331-345.

51. Hazra A, Wu K, Kraft P, Fuchs CS, Giovannucci EL, Hunter DJ. Twenty-four non-synonymous polymorphisms in the one-carbon metabolic pathway and risk of colorectal adenoma in the nurses' health study. Carcinogenesis. 2007;28:1510-1519.

52. Curtin K, Slattery ML, Ulrich CM, et al. Genetic polymorphisms in one-carbon metabolism: Associations with cpg island methylator phenotype (cimp) in colon cancer and the modifying effects of diet. Carcinogenesis. 2007;28:1672-1679. 